\title{
Review
}

\section{Aspects of the involvement of interleukin-1 and nitric oxide in the pathogenesis of insulin-dependent diabetes mellitus}

\author{
Åke Sjöholm \\ Department of Molecular Medicine, The Endocrine and Diabetes Unit, The Rolf \\ Luft Center for Diabetes Research, Karolinska Institute, Karolinska Hospital \\ (L6:01B), S-171 76, Stockholm, Sweden. tel: +46851775782, \\ +46705234057; fax: +46851773658 (+468303458); e-mail: ake@enk.ks.se
}

Received 6.11.97; revised 2.2.98; accepted 9.2.98

Edited by G. Melino

\begin{abstract}
The possible involvement of the cytokine interleukin-1 (IL-1) and nitric oxide (NO) in the pathogenesis of insulin-dependent diabetes mellitus (IDDM) is reviewed and current and potential therapies are discussed. IDDM is a common disorder in the Western world and it is rising in incidence. In IDDM, isletinfiltrating macrophages produce IL-1 which is cytotoxic specifically to $\beta$-cells in vitro. IL-1 increases $\beta$-cell formation of NO, ceramide, prostaglandins, heat-shock proteins, and activates a protease. Additionally, IL- 1 depresses $\beta$-cell energy production, insulin gene expression and cyclic AMP synthesis, and impacts negatively on different parts of the insulin stimulus-secretion coupling, actions mimicked by NO. Conversely, blocking NO formation prevented many of these effects in most reports published. Also, changes in cyclic AMP and prostaglandins seem unlikely events in mediating the cytotoxicity of IL-1, while the role of ceramide remains less clear. Peptides capable of blocking $\beta$-cell IL-1 receptors, and agents blocking NO synthesis may prove valuable in preserving $\beta$-cell function in IDDM. Although IDDM causes immense morbidity and expense, uniformly effective preventive or $\beta$-cell protective therapy is not currently available. If IL-1 is causing $\beta$-cell dysfunction in human IDDM through NO production, several processes in the IL-1-NO connection are appropriate targets for agents protecting $\beta$-cells from destruction and functional inhibition in IDDM.
\end{abstract}

Keywords: nitric oxide; interleukin-1; pancreatic islet; insulin secretion; diabetes mellitus

Abbreviations: AP, association protein; ATF, activated transcription factor; ATP, adenosine trisphosphate; cAMP, adenosine $3^{\prime}, 5^{\prime}$ cyclic monophosphate; cGMP, guanosine $3^{\prime}, 5^{\prime}$-cyclic monophosphate; COX, cyclooxygenase; DAG, 1,2-diacylglycerol; DNA, deoxyribonucleic acid; DTT, dithiothreitol; GTP, guanosine trisphosphate; IDDM, insulin-dependent diabetes mellitus; IL-1, interleukin-1; iNOS, inducible nitric oxide synthase; IRAP, IL-1 receptor antagonistic protein; JNK, janus kinase; NAD, nicotinamide dinucleotide; NF-KB, nuclear factor kappa B; NO, nitric oxide; NOD, non-obese diabetic; PCR, polymerase chain reaction; PG, prostaglandin; PKC, protein kinase C; PPase, protein phosphatase; RNA, ribonucleic acid; SIN-1, 3-morpholino-sydnonimine; SOD, superoxide dismutase; Sp-cAMP[S], Sp-diastereomer of cyclic adenosine-3',5'-monophosphothioate; TLCK, Na-p-tosyl-L-lysine chloromethyl ketone; TPA, 12-O-tetradecanoylphorbol-13-acetate

\section{Introduction}

Recognized since the time of Aristotle, diabetes mellitus remains a major health care problem in the Western world, afflicting $2-5 \%$ of the population. The disease is characterized by an absolute or relative deficiency of insulin, leading to vast derangements in glucose and lipid homeostasis with ravaging vascular complications. Insulin-dependent diabetes mellitus (IDDM) accounts for $\approx 10 \%$ of diabetes in Western societies, and is still rising in incidence among children and adolescents. IDDM is a chronic disease characterized by progressive destruction of the insulin-producing pancreatic $\beta$ cells in the islets of Langerhans (Tisch and McDevitt, 1996). Although the causes of this disease still remain largely elusive, evidence favors a role for autoimmune assault on the $\beta$-cells in genetically predisposed individuals, possibly triggered by viral infection (Tisch and McDevitt, 1996). Histologically, the endocrine pancreas shows heavy infiltration of immune cells, an event preceding the clinical outbreak of diabetes (Mandrup-Poulsen, 1996). It is now generally agreed that the pathogenesis of IDDM is primarily a cellmediated immune event, involving $\mathrm{CD}^{+}$(helper/inducer) and $\mathrm{CD}^{+}$(suppressor/cytotoxic) $\mathrm{T}$ cell subsets, as well as monocytes and macrophages (Mandrup-Poulsen, 1996).

In this paper, I will review extant data implicating the cytokine interleukin-1 (IL-1) and the free radical gas nitric oxide (NO) as key effectors in the pathogenesis of IDDM. Because of space limitations imposed, the reader will frequently be referred to more extensive reviews. A cap on references precluded citing key sources, and I apologize to the colleagues whose work could not be cited. Additionally, I will restrict myself to events occurring in islets once the immune system has been activated; however, excellent reviews on the autoimmune etiology of IDDM have been published (Tisch and McDevitt, 1996; Vyse and Todd, 1996).

\section{Interleukin-1: actions on islet $\beta$-cells and role in IDDM}

Some 10 years ago it was shown, by the pioneering work of Mandrup-Poulsen and associates, that supernatants from activated macrophages were cytotoxic towards $\beta$-cells in vitro 
(Mandrup-Poulsen, 1996). These islet-infiltrating leukocytes have been shown to produce a number of cytokines (Jiang and Woda, 1991), a group of soluble peptides with important messenger functions within the immune system. Interleukin$1 \beta$ (IL-1) is the best characterized of these and has been extensively studied for the past 10 years with regard to effects on the pancreatic islet cells in vitro (reviewed by MandrupPoulsen, 1996; Sandler et al, 1991). Extant data indicate that $\mathrm{IL}-1$ is able to exert both inhibitory and cytotoxic actions on islet $\beta$-cells in vitro (Mandrup-Poulsen, 1996; Sandler et al, 1991). Early investigators showed that IL-1 inhibits insulin secretion at least in part by selectively interfering with $\beta$-cell mitochondrial substrate oxidation, leading to $\mathrm{NAD}^{+}$depletion and a reduced energy production (Sandler et al, 1991). Glucose-sensitive insulin release seems to be preferentially affected, resembling the situation in pre-IDDM (Sandler et al, 1991). Additionally, insulin gene expression, and (pro)insulin biosynthesis is selectively affected by IL-1 (Sandler et al, 1991), supposedly resulting in the insulinopenia that characterizes IDDM.

These combined findings gave rise to the notion that IL-1 may be involved in the pathogenesis of IDDM (MandrupPoulsen, 1996). A brief (60 min) exposure of islets to IL-1 is sufficient to impose a long-lasting functional impairment by the $\beta$-cell (Eizirik et al, 1996). Because of repair systems activated, however, some $\beta$-cells are able to recover and if these cells are cultured for several days in the absence of the cytokine they regain their secretory activity (Eizirik et al, 1996).

On both normal and clonal $\beta$-cells, high-affinity cell surface receptors binding $\mathrm{IL}-1$ have been identified and partially characterized. It appears that these, like in macrophages, are of type- 1 and of approximately $80 \mathrm{kDa}$ is size (Sandler et al, 1991). Additionally, an IL-1 receptor antagonistic protein, named IRAP, has been shown to be co-secreted by macrophages (Mandrup-Poulsen, 1996). IRAP is $22 \mathrm{kDa}$ in size and shows $72 \%$ sequence homology to IL-1 (Mandrup-Poulsen, 1996). Maybe not so surprisingly, IRAP was shown to protect $\beta$-cells from IL-1 effects in vitro (Sandler et al, 1991). To exert its suppressive actions on the $\beta$-cell, IL-1 signals through multiple and complex pathways that obviously need gene transcription, mRNA translation, and de novo protein synthesis to result in an impeded $\beta$-cell function since the actions of the cytokine can be prevented by inhibitors of these processes (Welsh et al, 1991a). By means of 2dimensional gel electrophoresis, the expression of at least 33 islet proteins has been shown to be altered by IL-1 (Mandrup-Poulsen, 1996). The upregulation of some of these proteins probably reflects defense mechanisms mounted by the $\beta$-cell. For instance, different heat shock proteins, catalase, hemoxygenase, glutathione peroxidase, and superoxide dismutase (MnSOD), in other cell types are expressed under conditions of toxic stress or injury, and are induced by IL- 1 in the $\beta$-cell (Sandler et al, 1991; Welsh et al, 1995a). However, under basal conditions, rodent $\beta$-cell expression of these protective proteins is strikingly low and may contribute to the susceptibility of $\beta$-cells to autoimmune assaults and their inability to endure free radicals (Welsh et al, 1995a).
In order to ultimately find a means of intervening in the outbreak of IDDM, it is of paramount importance to pin down the subcellular mechanisms by which IL-1 exerts its inhibitory actions in the $\beta$-cell. Thus, the immediate events taking place after IL-1 occupancy of its cell surface receptor has been the subject of intense scrutiny during recent years. As in immune cells, a mechanism involving connection of $\mathrm{LL}-1$ receptor binding with the remainder of intracellular signaling, being mediated through low molecular weight GTP-binding proteins has been suggested in the $\beta$-cell (Mandrup-Poulsen, 1996). GTP-binding protein interference has been shown to partially account for the suppression of insulin secretion by epinephrine, somatostatin, galanin and E-type prostaglandins (Robertson et al, 1991). At least seven $G_{\alpha}$ subunits have been identified in rat islets by PCR strategies and in situ hybridization (Zigman et al, 1994). However, in contrast to the pertussis toxin-sensitive GTP-binding proteins regulating adenylyl cyclase and phospholipase C (Neer, 1995), the putative proteins involved in $\mathrm{IL}-1$ signaling in the $\beta$-cell appears to be of a different kind (Mandrup-Poulsen, 1996). Thus, pretreatment of $\beta$-cells with pertussis toxin prevented the suppressive effects of adrenergic agonists, but not those of IL-1 (Sjöholm, 1991a,b; 1992a,b; 1993; 1996a). The reported reduction in the content of cyclic AMP in IL-1treated islets (Sjöholm, 1991a,b; 1992a,b) might be suspected to contribute to the inhibitory actions of the cytokine on insulin secretion and DNA synthesis, since both these processes are stimulated by cyclic AMP (Sjöholm, 1992b; 1993; 1996b; Ämmälä et al, 1994; Newgard and McGarry, 1995). Addition of the stimulatory cyclic AMP analog Sp-cAMP[S] was found to increase $\beta$-cell DNA synthesis and insulin secretion (Sjöholm 1996c; 1997), but failed to affect the inhibitory action of IL-1 on these parameters (Sjöholm 1991a; 1992a). These findings indicate that the decrease in cyclic AMP elicited by IL-1 treatment is not responsible for the inhibition of DNA synthesis or insulin secretion evoked by the cytokine. Recent data also indicate that IL-1 may function through tyrosine kinase activation, because its actions in the $\beta$-cell were prevented by tyrosine kinase inhibitors (Corbett et al, 1993a).

The expression of a number of $\beta$-cell genes and transcription factors is altered by IL-1. Among these, the immediate-early response genes, c-fos and c-jun, are rapidly $(30-60 \mathrm{~min})$ and transiently induced by $\mathrm{IL}-1$ (Welsh, 1996). Additionally, IL-1 appears to activate p38 mitogen-activated protein kinase and JNK-1 (MandrupPoulsen, 1996) and the transcription factors AP-1 and ATF-2 (Mandrup-Poulsen, 1996; Welsh, 1996). In clonal insulinoma cells, IL-1 induces the expression of the antiproliferative gene p53, which may contribute to the growth inhibitory effect of IL-1 in this system (Sjöholm, 1991a,c; 1992a). Also, the transcription factor NF- $\kappa \mathrm{B}$ is rapidly $(15-30 \mathrm{~min})$ translocated from the cytosol to the nucleus, by a tyrosine kinase-dependent mechanism (Eizirik et al, 1996).

In other cell types, IL-1 has been shown to activate intracellular proteases. Recent evidence also in the $\beta$-cell suggests that an important event in IL-1 action might be 
protease activation, since a complete protection against IL1 inhibition of insulin production and secretion in adult rat islets can be afforded by certain serine protease inhibitors (Welsh et al, 1991b; Sjöholm, 1991a), such as No-p-tosyl-Llysine chloromethyl ketone (TLCK). The tosyl-lysine group of TLCK forms a complex with enzymes recognizing basic and hydrophobic amino acid residues, whereas the chloromethyl ketone group accounts for irreversible inactivation of the enzyme by alkylating a catalytically active histidine.

\section{IL-1 stimulates islet nitric oxide formation and causes apoptotic $\beta$-cell death?}

Since the original discovery of the involvement of the noxious free radical gas nitric oxide (NO) in IL-1-mediated suppression of $\beta$-cell function (Southern et al, 1990), a considerable amount of compelling evidence suggest that a primary, mandatory event in IL-1 inhibition of $\beta$-cell function involves generation of NO (reviewed by Mandrup-Poulsen, 1996; McDaniel et al, 1996). This may be of particular clinical relevance, since epidemiological studies have demonstrated an increased incidence of IDDM in populations with high intake of dietary nitrites, possibly because of formation of diabetogenic nitrosoamines (Virtanen et al, 1994; Kostraba et al, 1992; Helgason et al, 1982). NO is highly unstable and is readily converted into its stable end products nitrite and nitrate (Bredt and Snyder, 1994). According to the contemporary conceptual framework, IL- 1 increases $\beta$-cell formation of NO by inducing the expression of NO synthase (iNOS [McDaniel et al, 1996]) after a lag period of 3-6 h. The enzyme catalyzes the release of NO from L-arginine (Bredt and Snyder, 1994). This process requires transcription and enzyme synthesis and is preceded by induction of c-fos, cjun, and the transcription factor NF- $\kappa \mathrm{B}$ (Eizirik et al, 1996). However, c-fos and c-jun apparently do not regulate iNOS gene expression. It was recently shown that TLCK prevented both NF- $\kappa \mathrm{B}$ expression and NO formation induced by $\mathrm{IL}-1 \beta$ in the $\beta$-cell.

Aside from stimulating $\beta$-cell iNOS, IL-1 may also promote NO release from resident macrophages, and act as a chemoattractant to recruit other immune cells to the insulitis lesion. In the islet, iNOS expression seems restricted to the $\beta$-cell (McDaniel et al, 1996; Eizirik et al, 1996). The $\beta$-cell $130 \mathrm{kDa} \mathrm{Ca}{ }^{2+}$-independent iNOS resembles that expressed in macrophages, and is located on chromosome 17 (Eizirik et al, 1996). The enzyme appears to be feedback inhibited by NO itself, probably by decreasing iNOS transcription (Eizirik et al, 1996). By contrast, iNOS mRNA degradation occurs rapidly, and is not affected by IL-1 (Eizirik et al, 1996). The regulation of $\beta$ cell iNOS is complex, and has recently been reviewed (Eizirik et al, 1996). The functional significance of NO generation is underscored by findings showing a complete protection against IL-1-induced $\beta$-cell dysfunction by specific inhibitors of NO synthase, e.g. arginine analogs (Southern et al, 1990; Corbett et al, 1993a). There is also a constitively expressed $\mathrm{Ca}^{2+}$-dependent NOS (cNOS), producing low amounts of $\mathrm{NO}$ needed to maintain vascular tone and neuronal synaptic transmission (Bredt and
Snyder, 1994). It is of interest that aminoguanidine selectively inhibits iNOS (McDaniel et al, 1996). Being a highly reactive, low molecular weight radical, NO is able to rapidly interact with a variety of target molecules (Bredt and Snyder, 1995). For instance, NO seems to cause ultrastructural damage and internucleosomal DNA fragmentation characteristic of apoptosis in cultured rodent $\beta$-cells.

Apart from NO, oxygen radicals such as hydroperoxide and superoxide are also formed within the insulitis lesion (Mandrup-Poulsen, 1996). It seems that enzymes scavenging oxygen radicals could not protect from IL-1 toxicity, when being introduced into $\beta$-cells by means of liposomal delivery (Welsh et al, 1994a). Recently, the regulation of the expression of MnSOD, which removes free radicals superoxide and peroxynitrite, has been studied (Eizirik et al, 1996). MnSOD mRNA is induced by IL-1 independently of protein synthesis and NO formation, indicating that IL-1 activates genes involved in $\beta$-cell defense and injury by different mechanisms. Furthermore, NF-KB activation appears to be required for iNOS, but not for MnSOD, mRNA expression in the $\beta$-cell.

One may ask whether effects of NO are conveyed by cGMP formation, as has been reported in many other cells (Bredt and Snyder, 1994). This is an attractive hypothesis since NO activates guanylyl cyclase by binding to iron in the heme at the enzyme's active site, thereby altering its conformation to augment catalysis (Bredt and Snyder, 1994). However, in the $\beta$-cell here are a number of indirect evidence against such a role for cGMP. Neither cellpermeable cGMP analogs, nor the guanylyl cyclase agonist atrial natriuretic peptide (Sjöholm, 1997) affected glucoseregulated insulin release in spite of the fact that $\beta$-cells express high-affinity receptors for this peptide, whose receptor has been shown to be identical to guanylyl cyclase.

Admittedly, most of the studies on IL-1 and NO effects have been carried out on isolated islets from rodents, and their pathogenic significance in human $\beta$-cells is still a matter of debate (Welsh et al, 1994b; Eizirik et al, 1996). It seems, from the few studies carried out on human islets so far, that $\beta$-cells from this species are much more resistant to both IL-1 and NO than their rodent counterparts (Welsh et al, 1994b). In particular, combinations of various other cytokines produced within the insulitis lesion (IL-1, interferon- $\gamma$ and tumor necrosis factor $\alpha$ ) appear to be needed to cause functional inhibition in human $\beta$-cells, whereas rat $\beta$-cells are sensitive to $\mathrm{IL}-1$ alone. Moreover, the human $\beta$-cell is less prone to form NO when exposed to cytokines, and seems also less susceptible to NO, than its rodent counterpart (Welsh et al, 1994b; Eizirik et al, 1996). Possibly, this can be explained by the higher expression of protective enzymes, e.g. heat shock proteins, catalase, hemoxygenase, glutathione peroxidase, and MnSOD, in human islets than in rodents (Welsh et al, 1995a).

It is noteworthy that serum from patients with IDDM, whose $\beta$-cells are succumbed by autoimmune assault, not only contains elevated levels of IL-1 (Hussain et al, 1996) but also causes exaggerated $\mathrm{Ca}^{2+}$ influx in clonal rat $\beta$-cells cells leading to DNA fragmentation characteristic of apoptosis (Juntti-Berggren et al, 1993), and that IL-1 
activates apoptosis in these cells through NO generation. Very recently, a number of papers have presented results arguing in favor of apoptosis as the mode of $\beta$-cell death in vivo in IDDM. For instance, by crossing a transgenic mouse carrying a $\beta$-cell-specific $\mathrm{T}$ cell receptor onto a NOD.scid background, it was possible to obtain an animal carrying $\mathrm{CD}^{+} \mathrm{T}$ cells bearing transgenic $\mathrm{T}$ cell receptor (but not $\mathrm{CD}^{+} \mathrm{T}$ cells or $\mathrm{B}$ cells). In this model, IDDM rapidly occurred and the mode of $\beta$-cell death was by apoptosis (Kurrer et al, 1997). In another study, it was found that IL-1 upregulated $\beta$-cell expression of Fas which led to $\beta$-cell apoptosis, apparently without the involvement of NO. This mechanism of $\beta$-cell death was recently confirmed in a transgenic mouse model (Chervonsky et al, 1997), in which Fas ligand was specifically overexpressed in the $\beta$-cell driven by the insulin promoter. These animals developed autoimmune diabetes through heightened sensitivity to diabetogenic $\mathrm{T}$ cells, due to self-destruction of $\beta$-cells upon $\mathrm{T}$ cell-mediated induction of Fas.

Previous findings in isolated insulin-secreting cells (Cooney et al, 1995) also showed that the vitamin $\mathrm{E} \gamma$ tocopherol, a major antioxidant in Western diets, could reverse the effects of IL-1, probably by detoxifying the nitrogen dioxide formed thereby preventing lipid peroxidation (Cooney et al, 1993). Interestingly, in vivo administration of E-vitamin was found to decrease or delay the onset of IDDM in BB rats (Murthy et al, 1992), and to reduce the incidence of IDDM in the NOD mouse (Hayward et al, 1992). Alluding to this, our previous studies on the role of prooxidants in $\beta$-cells has shown that quinone-induced oxidative stress activates programmed cell death in clonal insulinoma cells (Dypbukt et al, 1994).

Figure 1 provides a highly simplified view of intracellular events affected by IL-1 and NO in the $\beta$-cell.

\section{Role of lipid signaling in IL-1-exposed islets}

Lipid signaling is a versatile system by which cells transduce external messages into biological responses (reviewed by Divecha and Irvine, 1995; Nishizuka, 1995). In $\beta$-cells, plasma membrane phosphoinositide hydrolysis occurs early in secretory stimulation (Newgard and McGarry, 1995). Besides NO formation, generation of ceramide through the

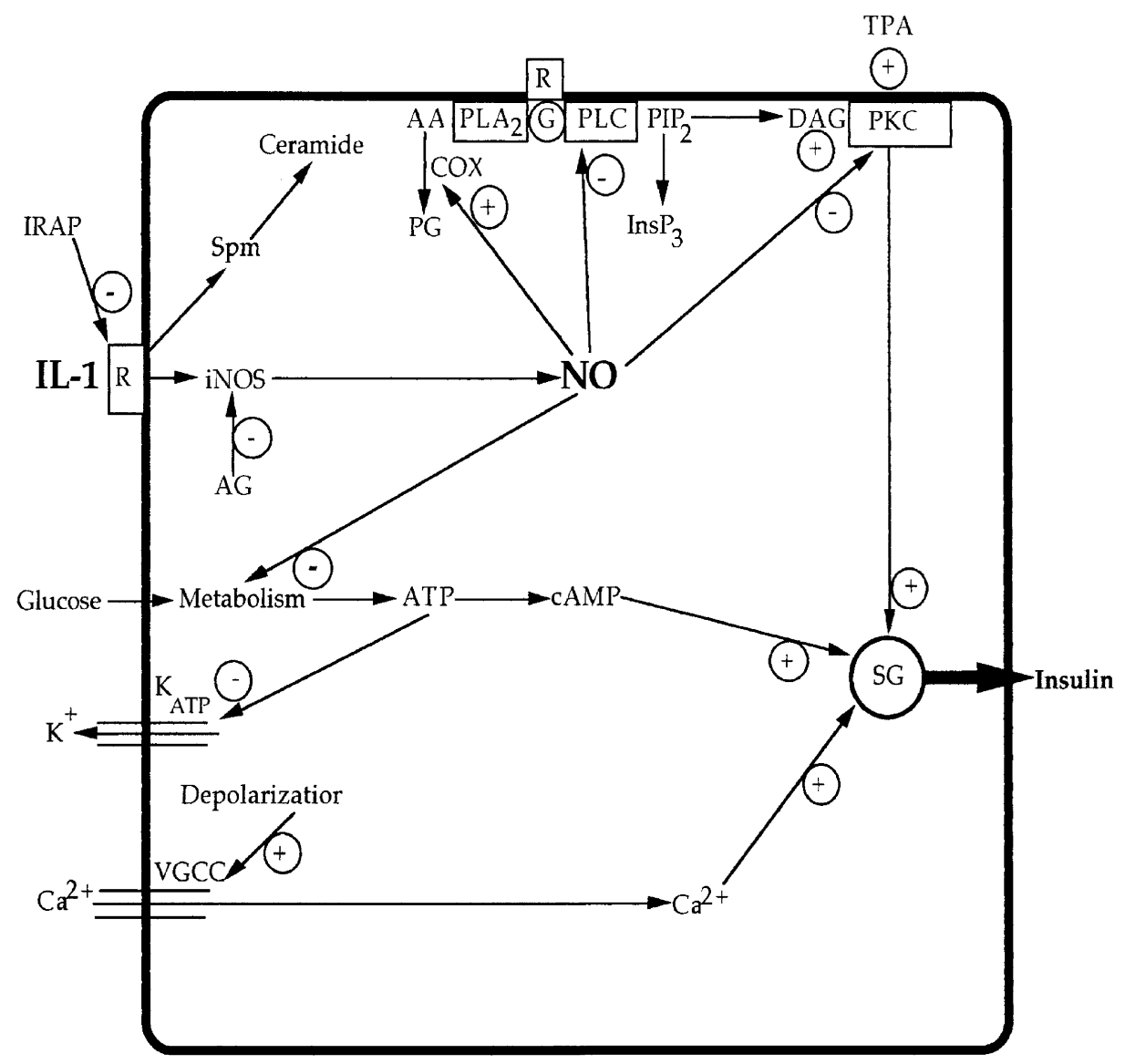

Figure 1 Working hypothesis for inhibitory effect of IL-1 and NO on $\beta$-cell function. +, stimulation; - , inhibition. AA, arachidonic acid: AG, aminoguanidine; ATP, adenosine trisphosphate; cAMP, adenosine 3', 5'-cyclic monophosphate; COX, cyclooxygenase; DAG, 1,2-diacylglycerol; G, GTP-binding protein; IL-1, interleukin1 ; iNOS, inducible nitric oxide synthase; InsP $\mathrm{P}_{3}$, inositol 1,4,5-trisphosphate; IRAP, IL-1 receptor antagonistic protein; $\mathrm{K}_{\text {ATP }}$, ATP-regulated $\mathrm{K}^{+}$channel; NO, nitric oxide; PG, prostaglandin; $\mathrm{PIP}_{2}$, phosphatidylinositol 4,5-bisphosphate; PKC, protein kinase C; $\mathrm{PLA}_{2}$, phospholipase $\mathrm{A}_{2}$; PLC, phospholipase C; R, receptor; SG, secretion granule; Spm, sphingomyelin; TK, tyrosine kinase; TLCK, Na-p-tosyl-L-lysine chloromethyl ketone; TPA, 12-Otetradecanoylphorbol-13-acetate; VGCC, voltage-gated $\mathrm{Ca}^{2+}$ channel. See text for details 
action of sphingomyelinase is a rapid and consistent event after exposure to IL-1 and other cytokines, e.g. interferon- $\gamma$ and tumor necrosis factor $\alpha$ (Hannun and Obeid, 1995). This event was also recently confirmed the $\beta$-cell, and it was suggested that IL-1-induced ceramide and diacylglycerol generation may lead to activation of the c-jun $\mathrm{NH}_{2}$-terminal kinase and transcription factor ATF2, but not NF-KB (Welsh, 1996). In contrast to the large wealth of information accumulating regarding products of phosphoinositide hydrolysis as regulatory molecules, the sphingolipids have been poorly appreciated and were until recently merely perceived as structural components of the plasma membrane. However, a rapidly growing body of evidence implicate ceramide, generated through sphingomyelin hydrolysis, as a novel second messenger, conveying antiproliferative signals by cytotoxic molecules such as IL-1 (reviewed by Hannun and Obeid, 1995). It seems that ceramide activates a p97 kinase thereby phosphorylating and activating p38 mitogenactivated protein kinase and JNK-1 (Mandrup-Poulsen, 1996). It is noteworthy that ceramide seems to counteract the effects of the phosphoinositide cleavage product diacylglycerol, the latter being an activator of PKC and linked to growth promotion and stimulation of insulin release (Sjöholm, 1991d; 1992b; 1993; 1996b; Ämmälä et al, 1994; Newgard and McGarry, 1995; Nishizuka, 1995; Arkhammar et al, 1994; Sjöholm et al, 1993a). Thus, although ceramide reportedly does not inhibit PKC, it has emerged as a second messenger mediating growth suppression and apoptosis (Hannun and Obeid, 1995) and may well prove to be as paramount as diacylglycerol in regulation of cell signaling. Additionally, specific targets for ceramide have been identified, including activation of a serine/threonine protein phosphatase of the $2 \mathrm{~A}$ subfamily, the latter recently being identified by us in $\beta$-cells (Ämmälä et al, 1994; Sjöholm et al, 1993b; 1995; Larsson et al, 1997). The recent development of cell-permeant ceramide analogs has made elucidation of the role of ceramide in living cells become amenable and conclusive (Hannun and Obeid, 1995). It appears that ceramide regulates the expression of $c-m y c$ levels and the transcription factor NF-KB, and is also able to interact with phospholipase $\mathrm{A}_{2}$ and cyclooxygenase (Hannun and Obeid, 1995), which are also affected by IL-1 (Hannun and Obeid, 1995; Mandrup-Poulsen, 1996). Whether any of these elements are targeted by ceramide also in the $\beta$-cell remains to be seen.

Previous findings show that exogenous ceramide suppresses $\beta$-cell growth and function, and also that artificially stimulating generation of ceramide in the $\beta$-cell by addition of the normally membrane-bound enzyme sphingomyelinase gave rise to qualitatively similar results (Sjöholm, 1995). This also mimicked the suppressive actions of IL-1, a pathophysiological effector of ceramide synthesis and $\beta$-cell death, thus adding further credence to a role of ceramide as a second messenger mediating cytotoxic signals by molecules such as IL-1. Entirely consistent with the above results are the previous findings that specific inhibition of serine/threonine protein phosphatase 2A with low concentrations of okadaic acid (Ämmälä et al, 1994; Larsson et al, 1997) or protein kinase C stimulation with phorbol ester (Sjöholm, 1991d; 1992b;
1993; 1996b; Ämmälä et al, 1994; Newgard and McGarry, 1995; Arkhammar et al, 1994; Sjöholm et al, 1993a) promotes insulin secretion and that insulin secretagogues transiently suppress $\beta$-cell PPase activities (Sjöholm et al, 1995). Conversely, nanomolar concentrations of okadaic acid or phorbol ester prevent apoptosis and c-myc downregulation evoked by ceramide (Hannun and Obeid, 1995). Thus, ceramide and diacylglycerol appear to be the Yin and Yang of cellular signaling through their opposing effects on protein phosphorylation.

\section{NO impacts negatively on the $\beta$-cell insulin stimulus-secretion coupling}

In a recent paper, the influence of the NO donor 3morpholino-sydnonimine (SIN-1) on the regulation of discrete parts of the stimulus-secretion coupling in isolated pancreatic islets has been investigated (Sjöholm, 1996d). The insulin secretory response to the cardinal insulin secretagogue glucose was preferentially impeded following SIN-1 exposure, resembling the situation noted with IL-1 (Sandler et al, 1991). It is currently believed that glucose metabolism in the cytosolic Emden-Meyerhof pathway, and after funneling into mitochondria, further oxidative catabolism in the Krebs cycle, generates signals that promote insulin secretion (Newgard and McGarry, 1995). It is moreover believed that the ATP generated through the metabolism of the sugar blocks ATP-dependent $\mathrm{K}^{+}$channels in the plasma membrane, resulting in cell depolarization with the subsequent influx of $\mathrm{Ca}^{2+}$ through voltage-activated $\mathrm{Ca}^{2+}$ channels, an event that sets in motion the exocytotic release of insulin (Rorsman et al, 1990; Wollheim and Sharp, 1981). Thus, it is evident that the reported effects of SIN-1 may reflect NO interaction with any of these steps, or others, activated by hexose stimulation. One striking feature of $\mathrm{NO}$ is that it is able to bind to iron-sulfur enzymes, and thereby modulate their biological activity (Bredt and Snyder, 1994). One such example is the Krebs cycle enzyme cisaconitase, which was previously shown to be a major inhibitory target for $\mathrm{IL}-1$ and $\mathrm{NO}$ in the $\beta$-cell and possibly accounting for the reduced glucose oxidation by IL-1 (Welsh et al, 1991a). Obviously, inhibition of this enzyme would result in an impaired ATP production with secondary effects on ATP-dependent $\mathrm{K}^{+}$channels and $\mathrm{Ca}^{2+}$ entry. Additionally, by ADP ribosylation, NO can enhance incorporation of NAD into glyceraldehyde-3-phosphate dehydrogenase by modifying a cysteine at the active site of the enzyme, thereby potentially depressing glycolysis. Another biological feature of NO includes its ability to stimulate $S$-nitrosylation of various target proteins containing 'critical' $\mathrm{SH}$ groups (Bredt and Snyder, 1994; Lipton et al, 1993; Stamler, 1994). The precise nature of which proteins in the stimulus-secretion coupling that are targeted by $\mathrm{NO}$ in the thiol-dependent redox mechanisms reported (Sjöholm, 1996d), remains to be elucidated in forthcoming studies. However, in this context it is of interest to note that reversible redox reactions are of great regulatory significance in $\beta$-cell function (reviewed by Ammon and Mark, 1985).

Previous findings indicate that the stimulation of insulin secretion with carbachol was partially countered by SIN-1 
(Sjöholm, 1996d), suggesting that NO may have modified phospholipase $\mathrm{C}$ by means of $S$-nitrosylation, as was reported previously in other tissues. Indirect evidence in favor of this view comes from the fact that co-incubation with the disulfide reducing agent DTT partially offset the inhibitory action of SIN-1 (Sjöholm, 1996d). Stimulating insulin release by directly activating heterotrimeric GTPbinding proteins, connected to phospholipase $C$ and adenylyl cyclase, by AIF was not affected by SIN-1 (Sjöholm, 1996d). This finding indicates that NO apparently does not affect the GTP-binding proteins regulating insulin release in this system. By contrast, in other cells, NO has been reported to influence the function of GTPbinding proteins.

$\mathrm{SIN}-1$ impeded the insulin secretory response to protein kinase C (PKC) activation by phorbol ester (Sjöholm, 1996d), suggesting PKC inactivation by NO, possibly through $S$-nitrosylation. This is an attractive hypothesis since PKC has critical thiol residues that that influence its kinase activity and which can be oxidized by NO (Gopalakrishna et al, 1993). However, somewhat surprising, co-addition of DTT failed to reverse the inhibitory effect of SIN-1 on PKC-regulated insulin release (Sjöholm, 1996d). This indicates either that SIN-1 acts unrelated to $S$-nitrosylation in this case, or, alternatively, that NO permanently inactivated PKC, as has been reported previously (Gopalakrishna et al, 1993).

Cyclic AMP-stimulated insulin release was not influenced by SIN-1 (Sjöholm, 1996d). This finding differs from previous data in other tissues, that showed NO inhibition of adenylyl cyclase activity by $S$-nitrosylation of vicinal thiols in the calmodulin binding domain of the cyclase, an effect reversed by DTT or glutathione. However, it appears that in the $\beta$-cell, the cyclic AMP system is less sensitive to thiol oxidation than other parts of the stimulus-secretion coupling (Ammon and Mark, 1985).

There are several reports indicating that NO can regulate $\mathrm{Ca}^{2+}$ channels in cardiac myocytes (Kirstein et al, 1995), although it is not clear whether this is achieved through $S$ nitrosylation. However, contrasting to these reports, the $\beta$ cell $\mathrm{Ca}^{2+}$ channel seems more resistant to NO, as SIN-1 exerted no discernable effects on $\mathrm{K}^{+}$-stimulated insulin release (Sjöholm, 1996d).

In conclusion, these data suggest that NO inhibits insulin secretion from $\beta$-cells partly by $S$-nitrosylation of vicinal thiol residues, likely forming intramolecular disulfides, in key proteins in the stimulus-secretion coupling (Sjöholm, 1996d). The results seem to exclude heterotrimeric GTPbinding proteins, adenylyl cyclase or voltage-activated $\mathrm{Ca}^{2+}$ channels being inhibited by NO in the $\beta$-cell (Sjöholm, 1996d). This resembles the situation with IL-1, which does not appreciably inhibit the insulin secretory response to cyclic AMP-raising agents or depolarizing concentrations of L-arginine. By contrast, enzymes involved in glucose catabolism, phospholipase $\mathrm{C}$, protein kinase $\mathrm{C}$ or proteins regulating intracellular $\mathrm{Ca}^{2+}$ handling may be targeted by NO (see Figure 1 for overview). A cell-permeant methyl ester of the Krebs cycle intermediate succinate was found to circumvent IL-1-induced inhibition of glucose-sensitive insulin release (Eizirik et al, 1996). However, this does not exclude that inactivation of the enzymes targeted by SIN -1 described above impacts negatively on the secretory response to other insulin secretagogues than glucose, e.g. neurotransmittors. These adverse effects of $\mathrm{NO}$ on the $\beta$-cell stimulus-secretion coupling may be of importance for the development of the impaired insulin secretion characterizing diabetes mellitus.

\section{Role of prostaglandins in $\beta$-cell dysfunction induced by IL-1}

Generation of the inflammatory mediators prostaglandins (PG), thromboxanes and leukotrienes through the concerted action of phospholipase $A_{2}$, cyclooxygenase and 12lipoxygenase is a consistent event after exposure to IL-1 in many tissues. Also in $\beta$-cells does IL-1 evoke a marked but delayed increase in $\mathrm{PGE}_{2}$ formation, the time course fitting the inhibitory phase of IL-1 action on insulin release (McDaniel et al, 1996). More recently, it was shown that IL-1 induces a cooperative expression of NO synthase and the inducible cyclooxygenase type 2 (iCOX) in rat islets, the activation of the latter enzyme apparently being mediated by $\mathrm{NO}$ and requiring RNA transcription (Corbett et al, 1993b). Recently it was also demonstrated that IL-1 enhances islet 12lipoxygenase product generation by increasing the availability of nonesterified arachidonic acid through a NOdependent mechanism. Furthermore, chemotactic leukotrienes may be produced through 5 -lipoxygenase expressed in islet resident macrophages (McDaniel et al, 1996). Interestingly, ceramide may assist in the phosphorylation and activation of phospholipase $A_{2}$ and may thereby, together with $\mathrm{NO}$, mediate the stimulatory effect of $\mathrm{IL}-1$ on islet prostaglandin formation (Mandrup-Poulsen, 1996). It is possible that locally produced prostaglandins may exert critical regulatory actions on $\beta$-cell growth and function and it is conceivable that they adversely influence insulin secretion and glucose homeostasis in vivo. Indeed, experiments in intact animals and in humans revealed that prostaglandin infusion decreased the amount of insulin secreted in response to an intravenous glucose challenge (Robertson, 1979). As a corollary to this, certain cyclooxygenase inhibitors have been reported not only to augment glucose-induced insulin responses in normal humans, but also to improve glucose disposal rates and glucose-sensitive insulin secretion in patients with NIDDM (Robertson, 1979). Previous studies have shown that exogenous prostaglandins of the E-series cause long-term suppression of pancreatic $\beta$-cell mitogenesis and insulin secretion (Sjöholm, 1996e). There are also numerous reports indicating that prostaglandins function as inhibitors of short-term insulin secretion in vitro (reviewed by Robertson, 1979).

The mechanisms by which prostaglandins exert their multifarious actions still remain largely elusive. However, in other cell types cDNAs encoding thromboxane $A_{2}$ and prostaglandin $\mathrm{EP}_{3}$ receptor subtypes have been cloned and characterized. In addition, at least in $\beta$-cells, prostaglandins reportedly inhibit inositol phosphate generation and cyclic AMP formation, two events invariably connected to promotion of mitogenesis and insulin secretion (Sjöholm, 1992b; 1993). Germane to this, pertussis toxin pretreatment 
was found to partially alleviate the inhibition of phasic insulin secretion from a hamster insulinoma cell line (Robertson et al, 1991), arguing in favor of heterotrimeric GTP-binding proteins partially conveying the short-term inhibitory effect of prostaglandins in this cell line. By contrast, in long-term experiments involving normal $\beta$-cells reported (Sjöholm, 1996e), no such protection by pertussis toxin pretreatment was afforded. Thus, the finding that exogenous prostaglandins mimicked the inhibitory actions of IL-1 on $\beta$-cell mitogenesis and insulin secretion engendered interest in the possibility that endogenous prostaglandins indeed convey the suppressive signal by the cytokine, rather than merely being coexpressed. However, the findings that cyclooxygenase inhibitors failed to influence the inhibitory effects of IL-1 argues against this possibility (Sjöholm, 1996e). Nonetheless, the prostaglandins may be involved in exacerbating the proinflammatory response within the insulitis lesion.

\section{Intervention in the IL-1/NO pathway may preserve $\beta$-cell function in IDDM}

While insulin injection is clearly life-saving in IDDM patients, uniformly effective preventive or $\beta$-cell protective therapy is not currently available. If IL- 1 is causing $\beta$-cell dysfunction in human IDDM through NO production, several processes in the IL-1-NO connection are appropriate targets for agents protecting $\beta$-cells from destruction and functional inhibition in IDDM. The selective iNOS blocker aminoguanidine has been given to nonobese diabetic (NOD) mice in vivo (Corbett et al, 1993c), and was found to delay the outbreak of overt diabetes in these animals, but did not prevent the disease. IRAP, the naturally occurring IL-1 receptor antagonist (MandrupPoulsen, 1996), should also be employed in vivo in a similar setting. Overexpression of the normally low abundant radical scavenger enzymes in islets may prove beneficial to dispose of toxic radicals in islets. Notably, liposomal delivery of heat shock protein 70 into $\beta$-cells, was found to protect these cells against IL-1 suppression (Sandler et al, 1991). As discussed above, antioxidant E-vitamins have showed promising results both in vitro and in vivo (Cooney et al, 1993; Murthy et al, 1992; Hayward et al, 1992). Corticosteroids such as dexamethasone have been reported by some groups to afford protection against IL-1, probably by posttranscriptionally inhibiting iNOS, but also through iCOX inhibition (McDaniel et al, 1996). Nicotinamide, tested in vitro with variable results is currently being clinically tried (Sperling, 1997), but the promising results by some groups, reporting a delayed IDDM onset, need to be confirmed. One may also envisage that inhibitors of ceramide synthesis, prostanoid formation, and agents interfering in apoptosis (e.g. blockers of plasma membrane $\mathrm{Ca}^{2+}$ channels and intervention in the Fas system), may eventually become of clinical utility. Finally, one promising approach would be gene therapy. Indeed, recently a hybrid gene consisting of IRAP and the insulin gene was constructed and transfected into clonal insulinoma cells (Welsh et al, 1995b). The construct was stably expressed by these cells and conferred resistance against the inhibitory actions of IL-1 in these cells (Welsh et al, 1995b). It remains to be seen, however, whether any of these approaches also could afford protection in vivo against human IDDM. If so, the immense morbidity and expense caused by IDDM may be significantly reduced.

\section{Acknowledgements}

ÅS is the recipient of the 1994 Eli Lilly/EASD Research Fellowship in Diabetes and Metabolism. Work from my laboratory cited herein received financial support from Funds of the Karolinska Institute, the Swedish Medical Research Council (K98-03X-12550-01A), the Swedish Diabetes Association, the Swedish Society of Medicine, the Novo-Nordic Insulin Fund, Barndiabetesfonden, Åke Wiberg's Foundation, Magn. Bergvall's Fund, Fredrik and Inger Thuring's Foundation and Syskonen Svensson's Fund.

\section{References}

Ämmälä C, Eliasson L, Bokvist K, Berggren P-O, Honkanen RE, Sjöholm Å and Rorsman P (1994) Activation of protein kinases and inhibition of protein phosphatases play a central role in the regulation of exocytosis in the pancreatic $\beta$-cells. Proc. Natl. Acad. Sci. 91: 4343-4347

Ammon HPT and Mark M (1985) Thiols and pancreatic $\beta$-cell function: a review. Cell Biochem. Funct. 3: 157-171

Arkhammar P, Juntti-Berggren L, Larsson O, Welsh M, Nånberg E, Sjöholm Å, Köhler $M$ and Berggren P-O (1994) Protein kinase $C$ modulates the insulin secretory process by maintaining a proper function of the $\beta$-cell voltage-activated $\mathrm{Ca}^{2+}$ channels. J. Biol. Chem. 269: 2743-2749

Bredt DS and SnyderSH (1994) Nitric oxide: a physiologic messenger molecule. Ann. Rev. Biochem. 63: 175-195

Chervonsky AV, Wang Y, Wong FS, Visintin I, Flavell RA, Janeway CA Jr, Matis LA (1997) The role of Fas in autoimmune diabetes. Cell 89: 17-24

Cooney RV, Franke AA, Harwood PJ, Hatch-Pigott V, Custer LJ and Mordan LJ (1993) $\gamma$-Tocopherol detoxification of nitrogen dioxide. Superiority to $\alpha$ tocopherol. Proc. Natl. Acad. Sci. 90: 1771-1775

Cooney RV, Harwood PJ, Franke AA, Narala K, Sundström A-K, Bergren P-O and Mordan $\mathrm{LJ}(1995)$ Products of $\gamma$-tocopherol reaction with $\mathrm{NO}_{2}$ and their formation in rat insulinoma (RINm5F) cells. Free Rad. Biol. Med. 19: 259-269

CorbettJA, Sweetland MA, Lancaster Jr, JR and McDaniel ML (1993a) A 1-hour pulse with IL-1 $\beta$ induces formation of nitric oxide and inhibits insulin secretion by rat islets of Langerhans: Evidence for a tyrosine kinase signaling mechanism. FASEB J. 7: $369-374$

Corbett JA, Kwon G, Turk Jand McDaniel ML (1993b) IL-1 $\beta$ induces the coexpression of both nitric oxide synthase and cyclooxygenase by islets of Langerhans: Activation of cyclooxygenase by nitric oxide. Biochemistry 32: 13767-13770

Corbett JA, Mikhael A, Shimizu J, Frederick K, Misko TP, McDaniel ML, Kanagawa $O$ and Unanue ER (1993c) Nitric oxide production in islets from nonobese diabetic mice: aminoguanidine-sensitive and -resistant stages in the immunological diabetic process. Proc. Natl. Acad. Sci. 90: 8992-8995

Divecha N and Irvine RF (1995) Phospholipid signaling. Cell 80: 269-278

Dypbukt JM, Ankarcrona MM, Burkitt M, Sjöholm Å, Ström K, Orrenius S and Nicotera P. (1994) Different prooxidant levels stimulate growth, trigger apoptosis, or produce necrosis of insulin-secreting RINm5F cells. The role of intracellular polyamines. J. Biol. Chem. 269: 30553-30560

EizirikDL, Flodström M, Karlsen AE and WelshN (1996) The harmony of the spheres: inducible nitric oxide synthase and related genes in pancreatic $\beta$-cells. Diabetologia 39: 875-890.

Gopalakrishna R, Chen ZH and Gundimeda U (1993) Nitric oxide and nitric oxidegenerating agents induce a reversible inactivation of protein kinase $C$ activity and phorbol ester binding. J. Biol. Chem. 268: 27180-27185

Hannun YA and Obeid LM (1995) Ceramide: an intracellular signal for apoptosis. Trends Biochem. Sci. 20: 73-77

Hayward AR, Shriber M and Sokol R (1992) Vitamin E supplementation reduces the incidence of diabetes but not insulitis in NOD mice. J. Lab. Clin. Med. 119:503507

Helgason T, Ewen SWB, Ross IS and Stowers JM (1982) Diabetes produced in mice by smoked/cured mutton. Lancet ii: 1017-1022 
Hussain MJ, Peakman M, Gallati H, Lo SS, Hawa M, Viberti GC, Watkins PJ, Leslie RDG, Vergani D (1996) Elevated serum levels of macrophage-derived cytokines precede and accompany the onset of IDDM. Diabetologia 39: 60-69

Jiang Z and Woda BA (1991) Cytokine gene expression in the islets of the diabetic biobreeding/Worcester rat. J. Immunol. 146: 2990-2994

Juntti-Berggren L, Larsson O, Rorsman P, Ämmälä C, Bokvist K, Wåhlander K, Nicotera P, Dypbukt J, Orrenius S, Hallberg A and Berggren P-O (1993) Increased activity of L-type $\mathrm{Ca}^{2+}$ channels exposed to serum from patients with type I diabetes. Science 261: 86-90

Kirstein M, Rivet-Bastide M, Hatem S, Bénardeau A, Mercadier J-J and Fischmeister R (1995) Nitric oxide regulates the calcium current in isolated human atrial myocytes. J. Clin. Invest. 95: 794-802

Kostraba JN, Gay EC, Rewers M and Hamman RF (1992) Nitrate levels in community drinking waters and risk of IDDM. Diabetes Care 15: 1505-1508

Kurrer MO, Pakala SV, Hanson HL and Katz JD (1997) Beta cell apoptosis in T cellmediated autoimmune diabetes. Proc. Natl. Acad. Sci. 94: 213-218

Larsson O, Barker CJ, Sjöholm Å, Carlqvist H, Michell RH, Bertorello A, Nilsson T, Honkanen R, Mayr GW, Zwiller J and Berggren PO (1997) Inhibition of phosphatases and increased $\mathrm{Ca}^{2+}$ channel activity by inositol hexakisphosphate. Science 278: $471-474$

LiptonSA, Choi YB, Pan ZH, Lei SH, Chen HSV, Sucher NJ, Loscalzo J, Singel DJ and Stamler JS. (1993) A redox-based mechanism for the neuroprotective and neurodestructive effects of nitric oxide and related nitroso-compounds. Nature 364: 626-632

Mandrup-Poulsen T (1996) The role of interleukin-1 in the pathogenesis of IDDM. Diabetologia 39: 1005-1029

McDaniel ML, Kwon G, Hill JR, Marshall CA and Corbett JA. (1996) Cytokines and nitric oxide in islet inflammation and diabetes. Proc. Soc. Exp. Biol. Med. 211 24-32

Murthy VK, Shipp JC, Hanson C and Shipp DM (1992) Delayed onset and decreased incidence of diabetes in BB rats fed free radical scavengers. Diab. Res. Clin. Pract. 18: 11-16

NeerEJ (1995) Heterotrimeric G proteins: organizers of transmembrane signals. Cell 80: $249-257$

Newgard CB and McGarry JD (1995) Metabolic coupling factors in pancreatic $\beta$-cell signal transduction. Ann. Rev. Biochem. 64: 689-719

Nishizuka Y (1995) Protein kinase $C$ and lipid signaling for sustained cellular responses. FASEB J. 9: 484-496

Robertson RP (1979) Prostaglandins as modulators of pancreatic islet function. Diabetes 28: 943-948

Robertson RP, Seaquist ER and Walseth TF (1991) G proteins and modulation of insulin secretion. Diabetes 40: 1-6

Rorsman P, Berggren P-O, Bokvist K and Efendic' S (1990) ATP-regulated K ${ }^{+}$ channels and diabetes mellitus. News Physiol. Sci. 5: 143-147.

Sandler S, Eizirik DL, Svensson C, Strandell E, Welsh M and Welsh N. (1991) Biochemical and molecular actions of interleukin-1 on pancreatic $\beta$-cells. Autoimmunity 10: 241-253

Sjöholm $\AA$ (1991a) Inhibition of fetal rat pancreatic $\beta$-cell replication by interleukin- $1 \beta$ in vitro is not mediated through pertussis toxin-sensitive G-proteins, a decrease in cyclic AMP, or protease activation. FEBS Lett. 289: 249-252.

Sjöholm A (1991b) $\alpha$-Adrenergic inhibition of rat pancreatic $\beta$-cell replication and insulin secretion is mediated through a pertussis toxin-sensitive G-protein regulating islet cAMP content. Biochem. Biophys. Res. Commun. 180: 152-155

Sjöholm A (1991c) Cytokines inhibit proliferation and insulin secretion by rat insulinoma cells (RINm5F) non-synergistically and in a pertussis toxininsensitive manner. Immunol. Lett. 30: 81-86

Sjöholm ^ (1991d) Phorbol ester stimulation of pancreatic $\beta$-cell replication, polyamine content and insulin secretion. FEBS Lett. 294: 257-260

Sjöholm Å (1992a) Differential effects of cytokines on long-term mitogenic and secretory responses of fetal rat pancreatic $\beta$-cells. Am. J. Physiol. 263: C114-C120

Sjöholm $\AA$ (1992b) Intracellular signal transduction pathways that control pancreatic $\beta$-cell proliferation. FEBS Lett. 311: 85-90

Sjöholm A (1993) Invited review. Role of polyamines in the regulation of proliferation and hormone production by insulin-secreting cells. Am. J. Physiol. 264: C501 C518

Sjöholm Å, Arkhammar P, Welsh N, Bokvist K, Rorsman P, Hallberg A, Nilsson T, Welsh M and Berggren P-O (1993a) Enhanced stimulus-secretion coupling in polyamine-depleted insulinoma cells (RINm5F). An effect involving increased cytoplasmic $\mathrm{Ca}^{2+}$, inositol phosphate generation, and phorbol ester sensitivity. J. Clin. Invest. 92: 1910-1917
Sjöholm Å, Honkanen RE and Berggren P-O (1993b) Characterization of serine/ threonine protein phosphatases in insulin-secreting cells. Biosci. Rep. 13:349357

Sjöholm A (1995) Ceramide inhibits pancreatic $\beta$-cell insulin production and mitogenesis and mimicks the actions of interleukin-1 $\beta$. FEBS Lett. 367:283-286

Sjöholm Å, Honkanen RE and Berggren P-O (1995) Inhibition of serine/threonine protein phosphatases by secretagogues in insulin-secreting cells. Endocrinology 136: $3391-3397$

Sjöholm Å. (1996a) Interleukin-1 $\beta$ and GTP-binding proteins. Diabetologia 39: 243244

Sjöholm ^ (1996b) Effects of secretagogues on insulin biosynthesis and secretion in polyamine-depleted pancreatic $\beta$-cells. Am. J. Physiol. 270: C1105-C1110

Sjöholm $\AA$ (1996c) Lithium stimulation of rat pancreatic $\beta$-cell replication is mediated through pertussis toxin-sensitive GTP-binding proteins and occurs independently of cAMP, protein kinase $\mathrm{C}$ activation or $\mathrm{Ca}^{2+}$ influx. Diabetes 45 : $1057-$ 1062

Sjöholm A (1996d) Nitric oxide donor SIN-1 inhibits insulin release. Am. J. Physiol. 271: C1098-C1102

Sjöholm $\AA$ (1996e) Prostaglandins inhibit pancreatic $\beta$-cell replication and long-term insulin secretion by pertussis toxin-insensitive mechanisms but do not mediate the actions of interleukin-1 $\beta$. Biochim. Biophys. Acta 1313: 106-110

Sjöholm $\AA$ (1997) Glucose stimulates islet $\beta$-cell mitogenesis through GTP-binding proteins and by protein kinase $C$-dependent mechanisms. Diabetes 46: $1141-$ 1147

Southern C, Schulster D and Green IC (1990) Inhibition of insulin secretion by interleukin- $1 \beta$ and tumour necrosis factor- $\alpha$ via an L-arginine-dependent nitric oxide generating mechanism. FEBS Lett. 276: $42-44$

Sperling MA (1997) Aspects of the etiology, prediction and prevention of insulindependent diabetes mellitus in childhood. Ped. Clin. North. Amer. 44: 269-284

Stamler JS (1994) Redox signaling: nitrosylation and related target interactions of nitric oxide. Cell 78: 931-936

Tisch R and McDevitt H (1996) Insulin-dependent diabetes mellitus. Cell 85: 291 297

Virtanen SM, Jaakkola L, Räsänen L, Ylönen K, Aro A, Lounamaa R, Åkerblom HK, Tuomilehto J and the Childhood Diabetes in Finland Study Group (1994) Nitrate and nitrite intake and the risk for type 1 diabetes in Finnish children. Diabetic Medicine 11: 656-662

Vyse TJ and Todd JA (1996) Genetic analysis of autoimmune disease. Cell 85:311318

Welsh N, Eizirik DL, Bendtzen K and Sandler S (1991a) Interleukin-1 $\beta$-induced nitric oxide production in isolated rat pancreatic islets requires gene transcription and may lead to inhibition of the Krebs cycle enzyme aconitase. Endocrinology 129: 3167-3173

Welsh N, Bendtzen K and Sandler S (1991b) Influence of protease on inhibitory and stimulatory effects of interleukin $1 \beta$ on $\beta$-cell function. Diabetes $40: 290-294$

Welsh N, Margulis B, Bendtzen K and Sandler S (1994a) Liposomal delivery of antioxidant enzymes protects against hydrogen peroxide- but not interleukin-1 $\beta$ induced inhibition of glucose metabolism in rat pancreatic islets. J. Endocrinol. 143: $151-156$

Welsh N, Eizirik DL and Sandler S (1994b) Nitric oxide and pancreatic $\beta$-cell destruction in insulin-dependent diabetes mellitus: Don't take NO for an answer. Autoimmunity 18: 285-290

Welsh N, Margulis B, Borg LAH, Jernberg Wiklund H, Saldeen J, Flodström M, Mello MA, Andersson A, Pipeleers DG, Hellerström C and Eizirik DL (1995a) Differences in the expression of heat-shock proteins and antioxidant enzymes between human and rodent pancreatic islets: implications for the pathogenesis of insulin-dependent diabetes mellitus. Molecular Medicine 1: 806-820

Welsh N, Bendtzen K and Welsh M (1995b) Expression of an insulin/interleukin-1 $\beta$ receptor antagonist hybrid gene in insulin-producing cell lines (HIT-T15 and NIT1) confers resistance against interleukin- $1 \beta$-induced nitric oxide production. J. Clin. Invest. 95: 1717-1722

Welsh $\mathrm{N}$ (1996) Interleukin-1 $\beta$ induced ceramide and diacylglycerol generation may lead to activation of the $\mathrm{c}$-jun $\mathrm{NH}_{2}$-terminal kinase and transcription factor ATF2 in the insulin-producing cell line RINm5F. J. Biol. Chem. 271: 8307-8312

Wollheim CB and Sharp GWG (1981) Regulation of insulin release by calcium. Physiol. Rev. 61: 914-973

Zigman JM, Westermark GT, LaMendola J and Steiner DF (1994) Expression of cone transducin, $G_{z} \alpha$, and other $G$-protein $\alpha$-subunit messenger ribonucleic acids in pancreatic islets. Endocrinology 135: 31-37 